\title{
Observation of snowfall with a low-power FM-CW K-band radar (Micro Rain Radar)
}

\author{
Stefan Kneifel • Maximilian Maahn • \\ Gerhard Peters $\cdot$ Clemens Simmer
}

Received: 23 September 2010/ Accepted: 25 April 2011/Published online: 12 May 2011

(C) The Author(s) 2011. This article is published with open access at Springerlink.com

\begin{abstract}
Quantifying snowfall intensity especially under arctic conditions is a challenge because wind and snow drift deteriorate estimates obtained from both ground-based gauges and disdrometers. Ground-based remote sensing with active instruments might be a solution because they can measure well above drifting snow and do not suffer from flow distortions by the instrument. Clear disadvantages are, however, the dependency of e.g. radar returns on snow habit which might lead to similar large uncertainties. Moreover, high sensitivity radars are still far too costly to operate in a network and under harsh conditions. In this paper we compare returns from a low-cost, low-power vertically pointing FM-CW radar (Micro Rain Radar, MRR) operating at $24.1 \mathrm{GHz}$ with returns from a $35.5 \mathrm{GHz}$ cloud radar (MIRA36) for dry snowfall during a 6-month observation period at an Alpine station (Environmental Research Station Schneefernerhaus, UFS) at 2,650 m height above sea level. The goal was to quantify the
\end{abstract}

Responsible editor: B. Ahrens.

S. Kneifel ( $\square)$

Institute for Geophysics and Meteorology,

University of Cologne, Zülpicherstraße 49a,

50674 Cologne, Germany

e-mail: skneifel@meteo.uni-koeln.de

M. Maahn · C. Simmer

Meteorological Institute, University of Bonn,

Auf dem Hügel 20, 53121 Bonn, Germany

M. Maahn

Geophysical Department, University Centre in Svalbard,

$\mathrm{Pb}$. 156, 9171 Longyearbyen, Norway

G. Peters

Metek, Meteorologische Messtechnik GmbH,

Fritz-Straßmann Str. 4, 25337 Elmshorn, Germany potential and limitations of the MRR in relation to what is achievable by a cloud radar. The operational MRR procedures to derive standard radar variables like effective reflectivity factor $\left(Z_{\mathrm{e}}\right)$ or the mean Doppler velocity $(W)$ had to be modified for snowfall since the MRR was originally designed for rain observations. Since the radar returns from snowfall are weaker than from comparable rainfall, the behavior of the MRR close to its detection threshold has been analyzed and a method is proposed to quantify the noise level of the MRR based on clear sky observations. By converting the resulting MRR- $Z_{\mathrm{e}}$ into $35.5 \mathrm{GHz}$ equivalent $Z_{\mathrm{e}}$ values, a remaining difference below $1 \mathrm{dBz}$ with slightly higher values close to the noise threshold could be obtained. Due to the much higher sensitivity of MIRA36, the transition of the MRR from the true signal to noise can be observed, which agrees well with the independent clear sky noise estimate. The mean Doppler velocity differences between both radars are below $0.3 \mathrm{~ms}^{-1}$. The distribution of $Z_{\mathrm{e}}$ values from MIRA36 are finally used to estimate the uncertainty of retrieved snowfall and snow accumulation with the MRR. At UFS low snowfall rates missed by the MRR are negligible when comparing snow accumulation, which were mainly caused by intensities between 0.1 and $0.8 \mathrm{~mm} \mathrm{~h}^{-1}$. The MRR overestimates the total snow accumulation by about $7 \%$. This error is much smaller than the error caused by uncertain $Z_{\mathrm{e}}$-snowfall rate relations, which would affect the MIRA36 estimated to a similar degree.

\section{Introduction}

Precipitation radars usually operate at frequencies in the $\mathrm{X}$, $\mathrm{C}$ or $\mathrm{S}$ bands $(\sim 3-11 \mathrm{~cm}$ wavelength) within which precipitating particles still adhere to the Rayleigh regime. 
Higher frequency systems (3-8 $\mathrm{mm}$ wavelength, $\mathrm{W}$ and Ka-band) are used to investigate non-precipitating clouds and are thus often called cloud radars. Attenuation, especially due to liquid water, increases rapidly to higher frequencies and limits the use of cloud radars for investigation of clouds containing large amounts of liquid precipitation. Since cloud radars are sufficiently sensitive to cloud ice, and since attenuation by ice is comparably low, cloud radars have been increasingly used to analyze precipitating ice and snow clouds (e.g. Matrosov et al. 2008). Snowfall is the predominant type of precipitation in sub-polar and polar latitudes (e.g. Ellis et al. 2009), thus the accurate determination of frozen precipitation is important. Furthermore, snowfall plays an important role in the hydrological cycle of polar ice sheets and also strongly influences the Earth's energy balance through changes of surface albedo.

The deployment and operation of ground-based cloud radar systems is expensive due to high logistic efforts for installation and maintenance as well as large power consumptions. This is particularly true for mountainous or polar regions, where snowfall measurements are of special importance. If the focus can be narrowed to the lowest $3 \mathrm{~km}$, a possible solution in such an environment can be the use of low-power radar systems like for example the 24.1 GHz FM-CW Micro Rain Radar (MRR, e.g. Peters et al. 2002). The MRR was originally designed to provide vertical profiles of rain drop size distributions (DSD) by exploiting the Doppler spectra of the falling hydrometeors. It has been widely used for the observation of rain microphysics (Löffler-Mang et al. 1999; Peters et al. 2005; Tokay et al. 2009; Van Baelen et al. 2009; Yuter and Houze 2003) and the investigation of bright band properties (Cha et al. 2009). To the authors' knowledge its potential for the observation of snowfall has not yet been investigated. With its relatively low power consumption of $25 \mathrm{~W}(525 \mathrm{~W}$ during antenna heating) and the comparably small instrument dimensions the instrument is well suited to operate in areas with limited infrastructure and under harsh weather conditions.

In this study we analyze collocated measurements from a MRR and a standard $35.5 \mathrm{GHz}$ cloud radar (MIRA36), which were deployed as part of the TOSCA (Towards an Optimal estimation based Snowfall Characterization Algorithm) campaign during the winter season of 2008/2009 at an Alpine environment located at 2,650 m MSL. In Sect. 2 we shortly describe the measurement campaign and the specifications of the two radar systems. The different sensitivities of a 24.1 and a $35.5 \mathrm{GHz}$ radar to snowflake size distributions (SSD), particle shape and snow water content (SWC) are analyzed by radiative transfer (RT) simulations and discussed in Sect. 3. These results are used to derive a relation between the two effective reflectivity factors $\left(Z_{\mathrm{e}}\right)$ and thus to convert $24.1 \mathrm{GHz} Z_{\mathrm{e}} \mathrm{s}$ into $35.5 \mathrm{GHz}$ equivalent values. In Sect. 4, we describe the methods that are used to derive the relevant radar parameters from the MRR raw data because the standard procedures are unsuitable for snowfall observations. We also show how the noise level of the MRR, which is important for snowfall retrieval, can be derived from clear sky data. Based on the results of the RT simulations, we are able to quantitatively compare the two radar systems in Sect. 5. First, the remaining differences in terms of $Z_{\mathrm{e}}$ and terminal velocitiy $(W)$ obtained from both radar systems are discussed. Then a $Z_{\mathrm{e}}$-snowfall rate (SR) relation is applied to the TOSCA dataset in order to determine the expected errors in snow accumulation and surface SR caused by the limited sensitivity of the MRR. Concluding remarks are given in Sect. 6.

\section{Instrumentation and data}

During TOSCA a comprehensive set of ground-based instrumentation has been deployed at the Environmental Research Station Schneefernerhaus (UFS at 2,650 m MSL, Lat.: $\mathrm{N} 47^{\circ} 25^{\prime}$, Lon.: E10 $59^{\prime}$ ) at the Zugspitze Mountain, Germany, during the winter season 2008/09. A detailed description of the project and the instrument specifications are given in Löhnert et al. (2011) and Kneifel et al. (2010). UFS is ideally located for snowfall observation thanks to frequent occurrence of snowfall and the large variety of operational atmospheric observations. During TOSCA, the standard instrumentation (i.e. wind speed and direction, temperature, humidity, etc. measured by the German Weather Service, DWD) was extended with passive microwave radiometers (Kneifel et al. 2010), active radar and lidar systems, and several in situ instruments to qualify and quantify snowfall. In this study we concentrate on the observations by the MRR $(24.1 \mathrm{GHz})$ and the $35.5 \mathrm{GHz}$ cloud radar (MIRA36), which are described in more detail in the following subsections. The main specifications of the two radar systems are also given in Table 1 .

\subsection{Cloud radar (MIRA36)}

The MIRA36 cloud radar system (manufactured by METEK GmbH, Elmshorn, Germany) is a pulsed, vertically pointing $\mathrm{K}_{\mathrm{a}}$-band $(35.5 \mathrm{GHz}, \lambda=8.4 \mathrm{~mm})$ cloud radar (e.g. Melchionna et al. 2008). The radar provides vertical profiles of $Z_{\mathrm{e}}$, the mean vertical Doppler velocity $(W)$, the Doppler spectral width, and the linear depolarization ratio (LDR). The system at the UFS was operated with a range resolution of $30 \mathrm{~m}$ (lowest usable range gate at $300 \mathrm{~m}$ ) which leads to a maximum measurement height of $15 \mathrm{~km}$ above ground. A sensitivity of $-44 \mathrm{dBz}$ at $5-\mathrm{km}$ range 
Table 1 Main technical specifications of the $24.1 \mathrm{GHz}$ Micro Rain Radar and the $35.5 \mathrm{GHz}$ cloud radar MIRA36

\begin{tabular}{lll}
\hline & MRR & MIRA36 \\
\hline Frequency $(\mathrm{GHz})$ & 24.1 & 35.5 \\
Radar type & FM-CW & Pulsed \\
Transmit power & $50 \mathrm{~mW}$ & $30 \mathrm{~kW}$ (peak power) \\
Receiver & Single polarization & Dual polarization \\
Power consumption (radar only) & $25 \mathrm{~W}$ & $1 \mathrm{~kW}$ \\
Total power consumption & $525 \mathrm{~W}$ & $3.4 \mathrm{~kW}$ \\
$\quad$ including air condition and antenna heating) & & \\
Max. measuring range (km) & 6 & 30 \\
Range resolution (m) & $10-200$ & $15-60$ \\
No. of range gates & 30 & 500 \\
Antenna diameter (m) & 0.5 & 1 \\
Beam width (2-way, 6 dB) & $1.5^{\circ}$ & $0.6^{\circ}$ \\
\hline
\end{tabular}

allows detecting even high-level ice clouds. The complete MIRA36 system was installed in a thermally stabilized container to ensure optimal performance during harsh weather conditions (Fig. 1a). Additionally, the radar dish was equipped with a $1.5 \mathrm{~kW}$ heating system to avoid snow accumulation on the antenna.

\subsection{Micro Rain Radar}

The Micro Rain Radar MRR-2 (METEK) (Fig. 1b) is a vertical pointing, low-cost, frequency modulated continuous wave (FM-CW) Doppler radar operating at K-band (24.1 GHz, $\lambda=12.4 \mathrm{~mm}$ ) (Peters et al. 2002). Like MIRA36, the MRR is a coherent Doppler radar, but with lower sensitivity, a fewer number of range gates, lower angular resolution (larger beam width) and without the capability to observe cross-polarized echoes, which is required to determine $\mathrm{LDR}$. The $\mathrm{CW}$-operation allows the use of a low-power transmitter $(50 \mathrm{~mW})$, since the sensitivity of a coherent radar depends on the average and not on the peak transmit power. The instrument consists of a parabolic offset dish antenna with a $0.5 \mathrm{~m}$ effective aperture diameter. The height resolution can be varied from 10 to $200 \mathrm{~m}$ which determines together with the fixed 30 range gates, the system's maximum height range of 300-6,000 m. The whole system, containing receiver and data analysis unit, has a remarkably low power consumption of $25 \mathrm{~W}$. Optionally it is possible to heat the dish, which increases the total power consumption up to $\sim 525 \mathrm{~W}$. The heater is particular useful in case of wet snowfall and low wind speed conditions that favor the accumulation of snow on the dish. During TOSCA the MRR was continuously heated to ensure optimal performance.

\section{Radiative transfer}

The two radar systems operate at wavelengths of 12.4 and $8.4 \mathrm{~mm}$; thus the Rayleigh approximation valid for $\lambda \gg$ particle size cannot be applied to snowflakes. Radiative transfer (RT) calculations are used to investigate and quantify the differences of snowfall backscattering
Fig. 1 a $35.5 \mathrm{GHz}$ cloud radar (MIRA36) and b $24.1 \mathrm{GHz}$ Micro Rain Radar (MRR) installed at the Environmental Research Station Schneefernerhaus (UFS) at 2,650 $\mathrm{m}$ (MSL) during the TOSCA campaign 2008/2009
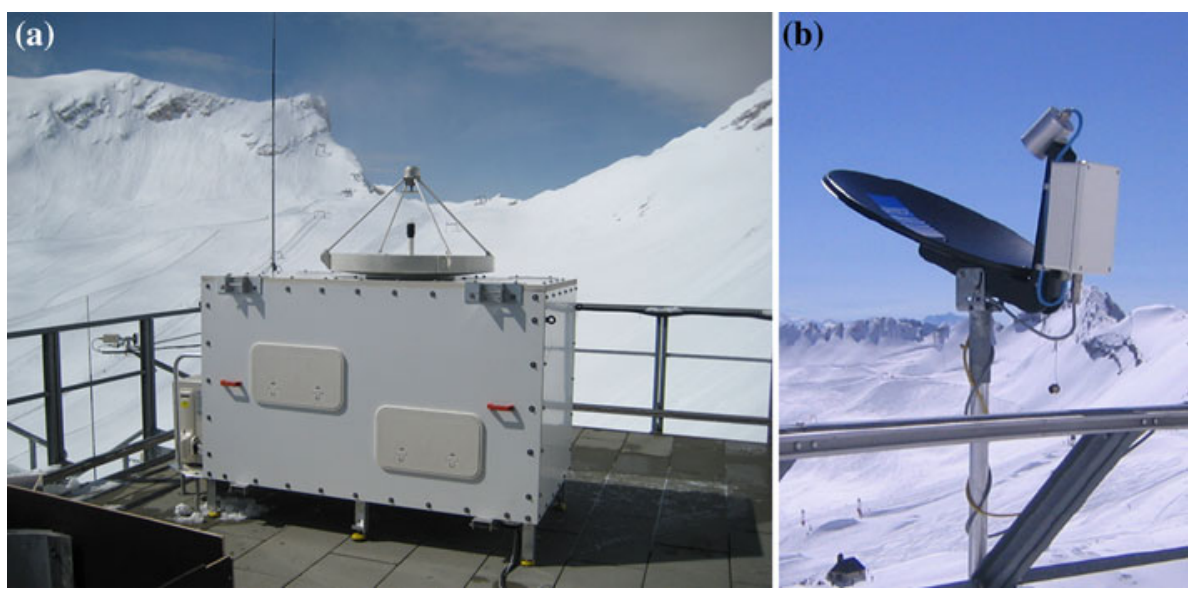
properties at the two radar frequencies and their dependency on particles size, SSD and SWC.

The RT3 model (Evans and Stephens 1991) is applied to simulate the propagation of electromagnetic radiation within a medium of randomly oriented particles. A standard mid-latitude winter atmosphere provides the profiles for air pressure, temperature and humidity. We concentrate on pure snow clouds while being aware that this is a simplification since airborne observations have revealed the frequent presence of super-cooled liquid cloud droplets within snow clouds (e.g. Boudala et al. 2004). We justify this simplification with the extremely low contribution of super-cooled cloud droplets to the total radar signal: For example, a cloud with an equal mass of snow and liquid water content (SWC, LWC) of $1 \times 10^{-4} \mathrm{~kg} \mathrm{~m}^{-3}$ produces a reflectivity factor at $35.5 \mathrm{GHz}$ of $-35 \mathrm{dBz}$ for the liquid cloud water component and $\sim 10 \mathrm{dBz}$ for the snow component (depending on snow particle shape and SSD assumptions, e.g. Kneifel et al. 2010).

In our RT simulations we assume different idealized snow crystals: 6-bullet rosettes (6bR), sector snowflakes (SEC) and dendrites (DEN) up to a maximum size of $10 \mathrm{~mm}$. Their single scattering properties are obtained from a database published by Liu (2008). The database also contains hexagonal plates and columns but their maximum particle size $(D)$ is much lower than for the other habits. Thus, they are less useful to simulate falling snow with a realistic spectrum of particle sizes. The backscattering properties of the chosen particles and especially their deviations from the Rayleigh approximation are illustrated in Fig. 2. When the backscattering cross sections $\sigma(D)$ at 35.5 and $24.1 \mathrm{GHz}$ are multiplied by $\lambda^{4}$ the size dependency for all particles within the Rayleigh approximation will follow the diagonal. As expected, the particles fit very well to the Rayleigh approximation up to particle sizes of $\sim 2.5 \mathrm{~mm}$. For further increasing particle sizes, the backscattering behavior approaches the Mie regime where especially dendrites (DEN) show deviations of up to one order of magnitude. Due to the higher frequency, the backscattering values at $35.5 \mathrm{GHz}$ reach the first Mie anomalies at larger sizes; hence the $35.5 \mathrm{GHz}$ backscattered signal becomes lower than the $24.1 \mathrm{GHz}$ signal.

The simulation of effective radar reflectivity factors requires assumptions about the SSD. As commonly used, we assume snow particles to be exponentially distributed according to

$N(D)=N_{0} \cdot \exp (-\Lambda D)$.

$N(D)\left(\mathrm{m}^{-4}\right)$ is the particle number density per particle size range, $N_{0}\left(\mathrm{~m}^{-4}\right)$ is the intercept parameter, and $\Lambda\left(\mathrm{m}^{-1}\right)$ the slope coefficient. Following results from ground-based measurements of SSDs (Braham 1990; Brandes et al. 2007) we vary $N_{0}$ between $1 \times 10^{6}$ and $1 \times 10^{8} \mathrm{~m}^{-4}$. Also the

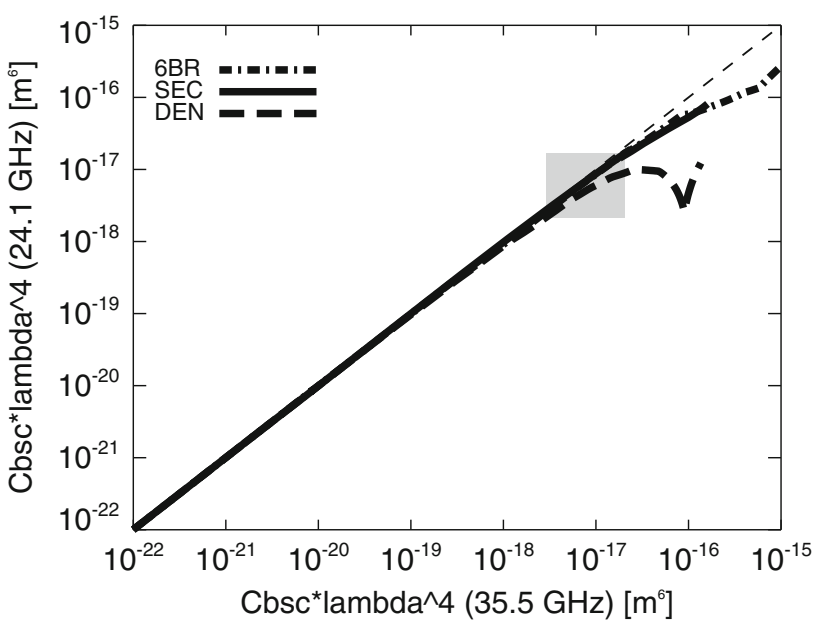

Fig. 2 Backscattering cross section multiplied with $24.1 / 35.5 \mathrm{GHz}$ wavelength $(\lambda)$ to the power of four $\left(\mathrm{m}^{6}\right)$ for snow particle types: 6-bullet rosettes (6BR, dashed dotted), sector snowflakes (SEC, dashed triple dotted) and dendrites (DEN, long dashed). The thin dashed line denotes the direct line. The corresponding particles have maximum sizes $\left(d_{\max }\right)$ between $100 \mu \mathrm{m}$ and $10 \mathrm{~mm}$. The grey shaded area marks values for associated particle size of $d_{\max }=2.5 \mathrm{~mm}$

snow water content (SWC) is varied between 0.05 to $0.5 \mathrm{~g} \mathrm{~m}^{-3}$. With the help of $N_{0}$ and the mass-size relation (given in the database for each particle type) the slope parameter $\Lambda$ can be calculated. Finally, the effective reflectivity factor $Z_{\mathrm{e}}$ in units of $\mathrm{mm}^{6} \mathrm{~m}^{-3}$ follows from

$Z_{e}=10^{18} \cdot \frac{\lambda^{4}}{\pi^{5} \cdot|K|^{2}} \int_{D_{\min }}^{D_{\max }} \sigma(D) N(D) \mathrm{d} D$

In Eq. 2, $\lambda$ is the wavelength in $\mathrm{m} ;|K|^{2}=0.92$ is related to the dielectric constant of liquid water ( $K$ is called the so-called dielectric factor), and $\sigma(D)$ is the backscattering cross section in $\mathrm{m}^{2}$. Due to the limitations of the scattering database the minimum particle dimension $D_{\min }$ is $100 \mu \mathrm{m}$ and the maximum particle dimension $\mathrm{D}_{\max }$ is 10 $\mathrm{mm}$. Attenuation effects due to atmospheric gases and snowfall are only a fraction of $1 \mathrm{~dB}$ for the considered frequencies (Matrosov 2007). Taking into account the limited height range of the MRR, attenuation effects are estimated to be below $0.5 \mathrm{~dB}$ and thus have been neglected.

The results of the RT simulations for different sets of SWC, $N_{0}$ and particle habits in terms of $Z_{\mathrm{e}}$ are shown in Fig. 3. As expected, $Z_{\mathrm{e}}$ values for 24.1 and $35.5 \mathrm{GHz}$ deviate most for SSDs with the high numbers of large particles (i.e. the smallest $N_{0}$ ). The largest differences of up to $7 \mathrm{~dB}$ are again obtained for DEN. These results imply that $Z_{\mathrm{e}}$ not only differ considerably for the two frequencies for $Z_{\mathrm{e}}$ values larger than $5 \mathrm{dBz}$ but also that a simple relation between $Z_{\mathrm{e}}$ at $35.5 \mathrm{GHz}$ and $Z_{\mathrm{e}}$ at 


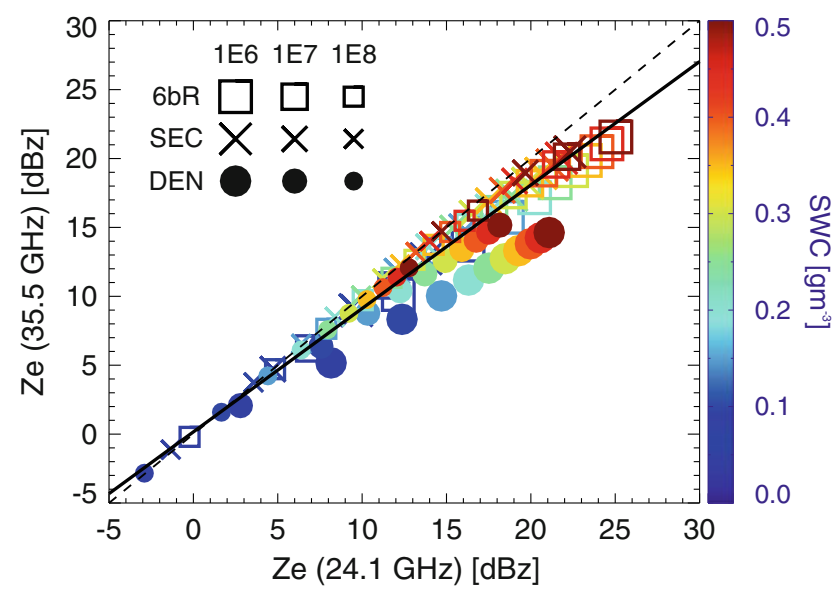

Fig. 3 Effective reflectivity factors $Z_{\mathrm{e}}$ in $\mathrm{dBz}$ from RT simulations for 35.5 and $24.1 \mathrm{GHz}$. The symbols denote the different snow particle types: 6-bullet rosettes (6BR, squares), sector snowflakes (SEC, crosses) and dendrites (DEN, spheres). The symbol size indicates the related $N_{0}$ value $\left(\mathrm{m}^{-4}\right)$ of the underlying snow size distribution ranging from $1 \times 10^{8}$ (smallest), $1 \times 10^{7}$ (middle) to $1 \times 10^{6}$ (largest). The color coding shows the snow water content $\left(\mathrm{SWC}, \mathrm{gm}^{-3}\right)$ of the related simulation. The dashed line denotes the direct line; the solid line results from a linear regression of combining all snowfall realizations

24.1 GHz can be obtained. Figure 3 demonstrates that distinct power law relations can be derived for every particle shape and $N_{0}$ combination. Knowing the real SSD and predominant particle shape (e.g. from optical particle probes), the appropriate coefficients can then be applied to the measured MRR $Z_{\mathrm{e}} \mathrm{s}$. Unfortunately, optical disdrometer observations are seldom available. Even with disdrometer data it is difficult to classify the true particle type since natural snowfall usually consists of a mixture of habits. Smaller snow particles more often resemble pristine crystals like dendrites or sector snowflakes while aggregates dominate the larger size spectrum. Various mixtures of plate like 2D particles and denser voluminous 3D snowflakes have been observed during TOSCA varying with the degree of riming and temperature/humidity conditions. Taking the observed variability into account, we believe that it is reasonable to derive an average relation by combining all different snowfall realizations and accept the fact that individual snowfall events can deviate from the mean relation. We postulate the following power law relation (transferred into a linear relation when using $\mathrm{dBz}$ units) to convert the $\mathrm{MRR} Z_{\mathrm{e}} \mathrm{s}$ into equivalent $35.5 \mathrm{GHz} Z_{\mathrm{e}} \mathrm{s}$

$10 \cdot \log Z_{e, 35.5 \mathrm{GHz}}=\alpha \cdot 10 \cdot \log Z_{e, 24.1 \mathrm{GHz}}+\beta$

The derived coefficients for Eq. 3 are $\alpha=0.896$ and $\beta=0.161$. These can then be applied e.g. to standard $\mathrm{Z}_{\mathrm{e}}-$ SR relations to derive surface SR from MRR observations.

\section{MRR data processing}

As a result of the MRR frequency modulation, the frequency of the received backscattered radiation deviates from the frequency of the currently transmitted signal due to the time delay caused by the distance of the backscattering particles from the radar. An additional frequency shift is produced by the Doppler shift $f_{\mathrm{D}}$ caused by the velocity of the particles relative to the radar. The MRR processing unit performs a two-dimensional Fourier analysis as described e.g. by Strauch (1976) to remove the range/Doppler ambiguity of FM-CW radars. As a result range resolved Doppler-induced power spectra are obtained which can be related to particle distributions via size dependent fall velocities. The operational software of the MRR automatically derives mean fall velocities, a rain DSD, a rain rate and a corresponding radar reflectivity factor $Z$ assuming liquid hydrometeors. For solid hydrometeors like snow the pertinent assumptions are violated; thus a simple adjustment of the operational output to snowfall is incorrect:

1. The DSD for raindrops is computed from the terminal fall velocity of the raindrops based on an assumed size-terminal velocity relation (Atlas et al. 1973). For snow particles, the size dependence of the terminal fall velocity is much weaker and-in addition-depends heavily on snow particle habit and the degree of riming (e.g. Brandes et al. 2008).

2. The backscattering cross section of spherical raindrops (oblate spheroids are not considered by the MRR) can be accurately calculated via Mie theory (e.g. LöfflerMang et al. 1999). Such relations are needed to derive the DSD from the observed backscattered radiation (see Peters et al. 2005, for a detailed description). Spherical and even spheroid approximations are, however, inappropriate especially for larger snowflakes (e.g. Petty and Huang 2010). Hence, the backscattering properties are largely dependent on snow particle habit.

3. Due to the low fall velocities of dry snowfall, turbulent air motion and larger scale updrafts strongly affect the Doppler spectra and cannot be separated easily from the fall velocity signals even if snow particle habit and the degree of riming is known.

4. The output reflectivity $Z$ of the MRR standard product ${ }^{1}$ is not derived from the spectrally (according to the Doppler spectrum) resolved reflectivity but from the inferred DSD via $Z=\int N(D) D^{6} \mathrm{~d} D$. This relation cannot be used mainly because of 1 and 3 .

\footnotetext{
${ }^{1}$ The MRR standard product is named instantaneous data oraveraged over an arbitrary time-average data.
} 
Fig. 4 Dealiasing and interpolation of the spectrum for an exemplary case with upward and downward moving particles. The reflectivities measured at the eighth range bin with a Doppler velocity between $6.06 \mathrm{~ms}^{-1}$ and $11.93 \mathrm{~ms}^{-1}$ (blue dotted) have in fact a Doppler velocity between -6.06 and $-0.189 \mathrm{~ms}^{-1}$ and originate from the seventh height bin (blue solid). The original frequency bins $0,1,63$ around $0 \mathrm{~ms}^{-1}$ are linearly interpolated (red)

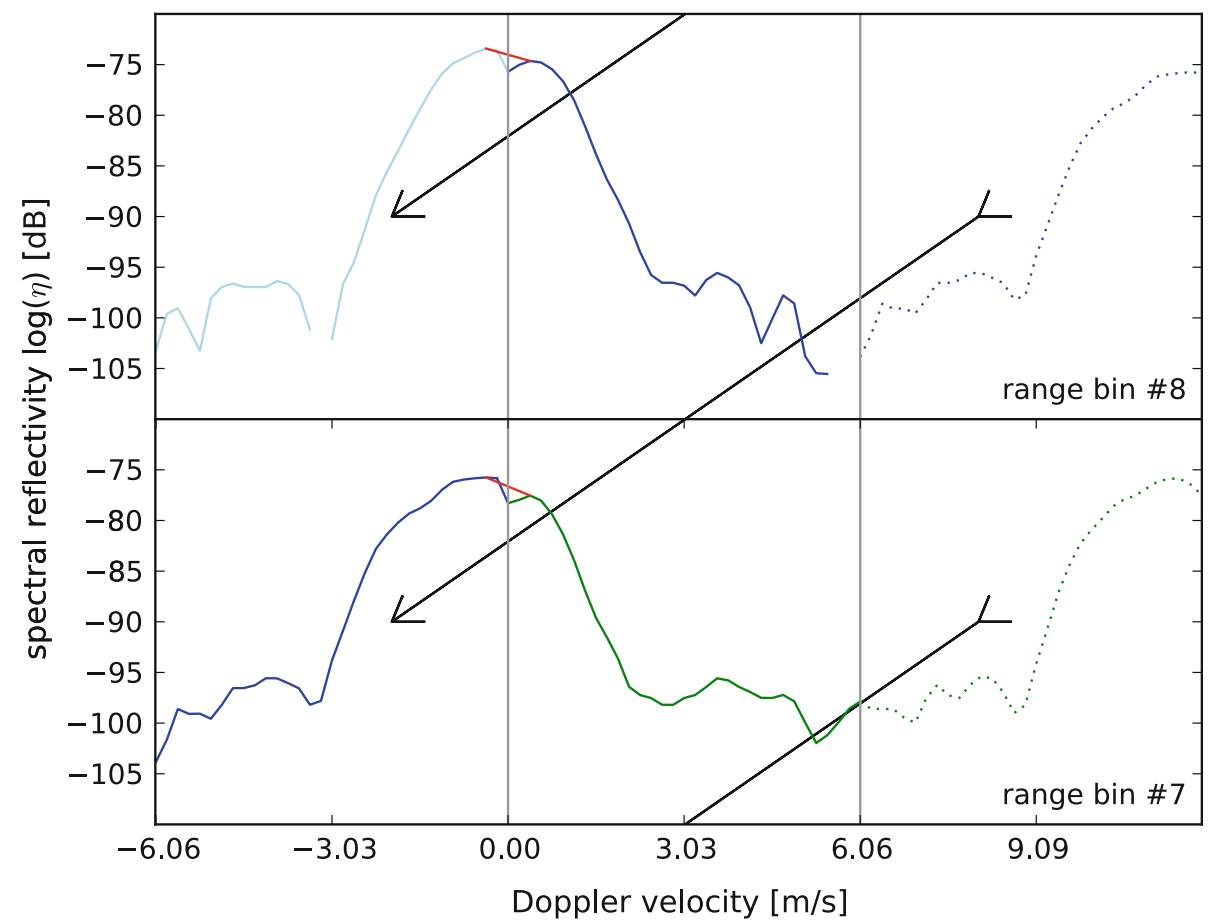

The arguments given in 1 to 4 reveal that we cannot derive a SSD from the Doppler spectra analogous to the rain case. To avoid any rain-specific assumptions we use instead the effective reflectivity factor $\left(Z_{\mathrm{e}}\right)$ in $\mathrm{mm}^{6} \mathrm{~m}^{-3}$, which is derived from the Doppler spectra using

$Z_{e}=10^{18} \cdot \frac{\lambda^{4}}{\pi^{5} \cdot|K|^{2}} \int_{-\infty}^{\infty} \eta\left(f_{D}\right) \cdot \mathrm{d} f_{D}$

$\lambda$ is the wavelength in $\mathrm{m} ;|K|^{2}=0.92$ is related to the dielectric constant of liquid water, and $\eta\left(f_{D}\right)$ is the spectral reflectivity $\left(\mathrm{sm}^{-1}\right)$ in dependence of Doppler frequency $f_{\mathrm{D}}$. The MRR standard data product contains $\eta(i)$ for all frequency bins $i$, thus the integral in (4) reduces to a summation over $i$. Since attenuation of the radar signal by dry snowfall is negligible at $\mathrm{K} / \mathrm{Ka}-$ band (Matrosov 2007) no attenuation correction has to be applied to $\eta(i)$. In the current MRR software version, $\eta$ are corrected for attenuation assuming liquid rain; this correction has to be disabled for snowfall observations.

\subsection{Dealiasing of the spectrum}

Due to the Fourier transformation procedures performed by the MRR firmware, the frequency resolution is limited to $30.52 \mathrm{~Hz}$, which corresponds to a terminal fall velocity resolution of $0.189 \mathrm{~ms}^{-1}$; thus the maximum number of 64 frequency bins limits the fall velocity range between 0 and $11.93 \mathrm{~ms}^{-1}$. The MRR assumes only positive fall velocities (defined here as movements toward the radar). This assumption is not always applicable to snowfall due to its much higher sensitivity to turbulence and related particle motions. In fact, the MIRA36 Doppler velocity measurements during TOSCA revealed frequent occurrences of upward particle motions especially at lower height levels while significant downward motions could not be identified. Such updrafts (or negative fall velocities) are currently misinterpreted by the MRR software as extremely high fall velocities due to the well-known velocity range aliasing typical for FM-CW Doppler radars (e.g. Strauch 1976). We correct such artifacts by the assumption, that dry snowflakes do not exceed fall velocities of $5.87 \mathrm{~ms}^{-1}$. Thus, the part of the $\eta$-spectrum corresponding to velocities above $5.87 \mathrm{~ms}^{-1}$ (frequency bins 33...64) is transferred to the negative fall velocity range $\left(-6.06 \ldots-0.189 \mathrm{~ms}^{-1}\right)$ of the succeeding range gate (Fig. 4). The FM-CW principle requires that signals with time independent phase need to be removed by appropriate filtering. As a consequence, the original frequency bins $i=64,1,2$ are disturbed and were omitted. However, due to the dealiasing of the spectrum the disturbed bins move from the border to the center of the spectrum and are reconstructed by linear interpolation. Following the definition used in the MRR standard product, the mean Doppler velocity $(W)$ is derived as the first moment of the dealiased Doppler spectrum.

\subsection{Evaluation of radar calibration}

To test the calibration of the MRR and the MIRA36 used in this campaign, their estimates of the radar reflectivity 
Table 2 Noise thresholds using 99\% quantile of the MRR clear sky noise: thresholds are derived from the $35.5 \mathrm{GHz}$ equivalent $Z_{\mathrm{e}}$ values

\begin{tabular}{lccccccccccc}
\hline Height $(\mathrm{m})$ & 500 & 600 & 700 & 800 & 900 & 1,000 & 1,100 & 1,200 & 1,300 & 1,400 & 1,500 \\
\hline Noise threshold (dBz) & -2.1 & -1.7 & -1.6 & -1.4 & -1.3 & -1.0 & -1.1 & -0.9 & -1.0 & -0.8 & -0.9 \\
Height (m) & 1,600 & 1,700 & 1,800 & 1,900 & 2,000 & 2,100 & 2,200 & 2,300 & 2,400 & 2,500 \\
Noise threshold (dBz) & -0.6 & -0.7 & -0.4 & -0.6 & -0.4 & -0.2 & -0.0 & -0.1 & 0.4 & 1.0 & \\
\hline
\end{tabular}

factor $Z$ for liquid precipitation at $600 \mathrm{~m}$ height were compared with $Z$ estimated by a PARSIVEL optical disdrometer (Löffler-Mang and Joss 2000). All three instruments derive $Z$ from the estimated DSD using the sixth moment of the DSD. The dataset from summer 2008 includes 54 rainy days with a total rain amount of $290 \mathrm{~mm}$ and a melting layer height above $800 \mathrm{~m}$ from the ground.

To exclude impacts both of shallow precipitation and attenuation effects, the comparison was limited to the reflectivity interval 5-20 dBz. For this interval, a stable mean offset of $-5 \mathrm{dBz}$ for the MRR and $+2.5 \mathrm{dBz}$ for the MIRA36 was found, which are considered as calibration offsets of the used instruments during TOSCA and have been corrected accordingly.

\subsection{Noise level}

Electronic and thermal noise cause an artificial background input power at any radar receiver even under clear sky conditions, which is removed dynamically by the MRR. ${ }^{2}$ With a perfect estimate of the mean noise level, the remaining $\eta$ would fluctuate around zero. Integrating the negative and positive $\eta$ over the entire frequency range according to (4) should result in $Z_{\mathrm{e}}$ values around zero (linear scale). Deviations from the white noise assumption and uncertainties of the noise level estimate, however, result in remaining non-zero $Z_{\mathrm{e}}$.

As a first guess assumption, we take the $99 \%$ quantile of the resulting $Z_{\mathrm{e}}$ distribution as a reasonable threshold to separate physical signal from noise. The noise thresholds used in this study are shown in Table 2 as $Z_{\mathrm{e}}$. Using the 99.5 (99.9)\% quantile instead raises the threshold only around $0.2(0.6) \mathrm{dBz}(35.5 \mathrm{GHz}$ equivalent). The noise thresholds were obtained from an analysis of 17 clear sky periods identified by ceilometer and cloud radar observations during the TOSCA period. The detectability is highest close to the ground with $-2 \mathrm{dBz}(35 \mathrm{GHz}$ equivalent) at $500 \mathrm{~m}$, but is decreasing with height to $3 \mathrm{dBz}$ at $3,000 \mathrm{~m}$. Due to variations in the electronic components of MRR instruments, the detectability profile is unique for each MRR.

${ }^{2}$ METEK GmbH, MRR Physical Basics, Version 5.2.0.3, Elmshorn, 20 pp, 2010.

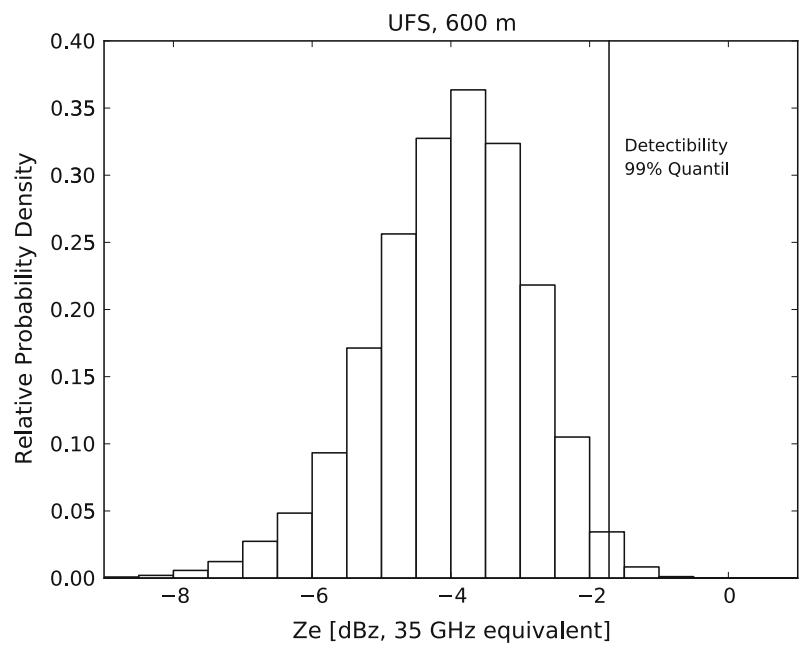

Fig. 5 Histogram of MRR clear sky noise at $600 \mathrm{~m}$ height based on 17 clear sky days derived from the temporal averaged (60 s) Doppler spectra in $\mathrm{dBz}$ (converted into $35.5 \mathrm{GHz}$ equivalent $Z_{\mathrm{e}}$ ). The vertical line denote the noise threshold in $\mathrm{dBz}(35.5 \mathrm{GHz}$ equivalent) defined as the $99 \%$ quantile

Since $\eta$ is stored logarithmically in the standard MRR product, an additional systematic positive bias in the derived $Z_{\mathrm{e}}$ is generated due to the omission of negative $\eta$ for clear sky cases. By manually reprocessing $\eta$ from the MRR raw data product and applying calibration, height and noise corrections to the raw data, this bias can be circumvented. The reprocessing of some exemplarily clear sky days improved, however, the detectability by only $0.2-0.3 \mathrm{dBz}^{3}$ Thus, this step is omitted in this study.

During the 6-month period, no significant temporal noise drift was observed. The $Z_{\mathrm{e}}$-probability density distribution is exemplarily presented for the $600 \mathrm{~m}$ height level in Fig. 5. In general, the width of the noise distribution depends on the total number of spectra and the averaging time used to calculate $Z_{\mathrm{e}}$. Here, an averaging time of $60 \mathrm{~s}$ was chosen; larger averaging times result in an even lower detectability threshold but at a loss of resolved temporal variability.

\footnotetext{
${ }^{3}$ This number was derived from an identical MRR in Longyearbyen, Norway. For TOSCA unfortunately no MRR raw data have been recorded.
} 


\section{Comparison of MRR with MIRA36}

In this section we apply relation (3) to real MRR data that were processed in the way described in Sect. 4. The applicability of the clear sky noise level estimate and $Z_{\mathrm{e}}$ conversion method is tested by comparing collocated measurements from the MRR and MIRA36. We analyze the complete 6-month TOSCA period which containsafter data quality checks -59 days with snowfall. We can assume that all precipitation particles are frozen since the 2-m temperatures during the observation time were always below $-5^{\circ} \mathrm{C}$.

The MIRA36 data have a range resolution of $30 \mathrm{~m}$ and a temporal resolution of $15 \mathrm{~s}$ while the MRR data have a range/temporal resolution of $100 \mathrm{~m}$ and $60 \mathrm{~s}$, respectively. To reduce differences that can arise from the different temporal/vertical resolution and different beam widths of the two instruments (Table 1), we averaged the MIRA36 data onto the MRR spatio-temporal grid. It is mentioned by the manufacturer of the MRR that the lowest 2-3 radar range gates are particularly influenced by instrument errors

(a)

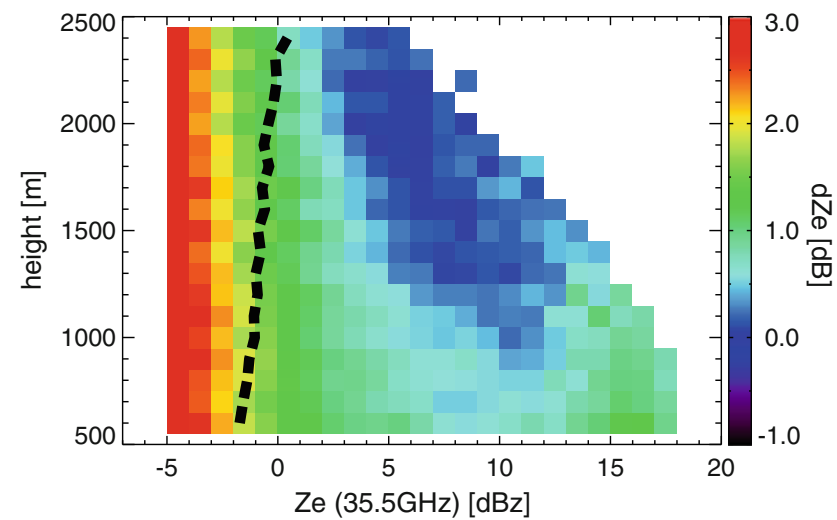

(c)

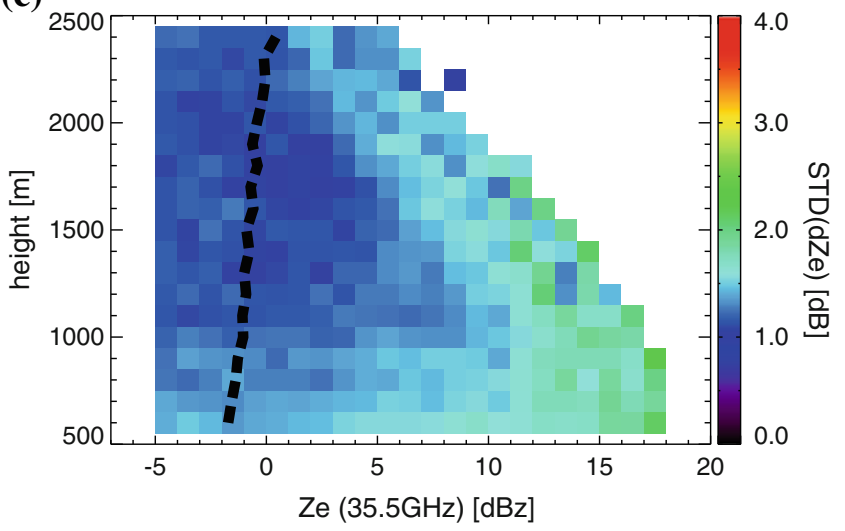

Fig. 6 Comparison of MRR and MIRA36 observations during TOSCA for a 6-month winter time period in 2008/2009. a Mean $Z_{\mathrm{e}}$ differences of MRR $(24.1 \mathrm{GHz})$ - MIRA36 $(35.5 \mathrm{GHz})\left(\mathrm{d} Z_{\mathrm{e}}\right)$ in $\mathrm{dB}$ as a function of height (m AGL) and MIRA36- $Z_{\mathrm{e}}$ value. The dashed black line denotes the MRR noise level derived from clear sky days and near field effects. We found that data at heights above $500 \mathrm{~m}$ and below $2,500 \mathrm{~m}$ are sufficiently free of disturbing effects and skipped all data outside this interval. All comparisons are presented as functions of MIRA36- $Z_{\mathrm{e}}$ and height above ground.

\subsection{Effective reflectivity factor $Z_{\mathrm{e}}$ and mean Doppler velocity $W$}

The $Z_{\mathrm{e}}$ values derived directly from the Doppler spectra are first compared without any frequency correction as mean differences $\left(\mathrm{d} Z_{\mathrm{e}}\right)$ between MRR and MIRA36 (Fig. 6a). The comparison reveals two main patterns:

The values of $Z_{\mathrm{e}}$ larger than the clear sky noise level show a mean $\mathrm{d}_{\mathrm{e}}$ of $0-2 \mathrm{~dB}$ that is greatest at the lower height levels $(600-1,300 \mathrm{~m})$. If the $Z_{\mathrm{e}}$ values fall below $0-1 \mathrm{dBz}$ the $\mathrm{d} Z_{\mathrm{e}}$ values increase significantly with a slight dependence on height. This behavior is a result of the very different sensitivity ranges of the two radars. While MIRA36 measures reflectivity factors down to $-44 \mathrm{dBz}$, the MRR reaches its noise level around $0 \mathrm{dBz}$. Reflectivity

(b)

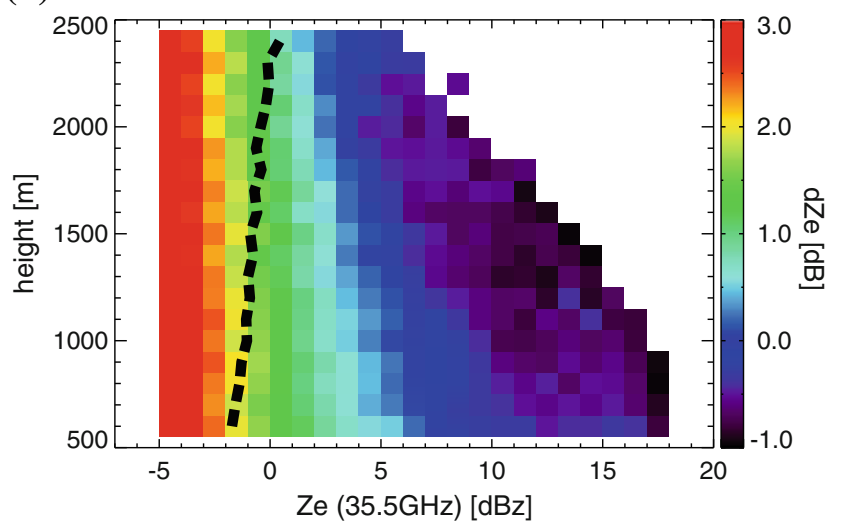

(d)

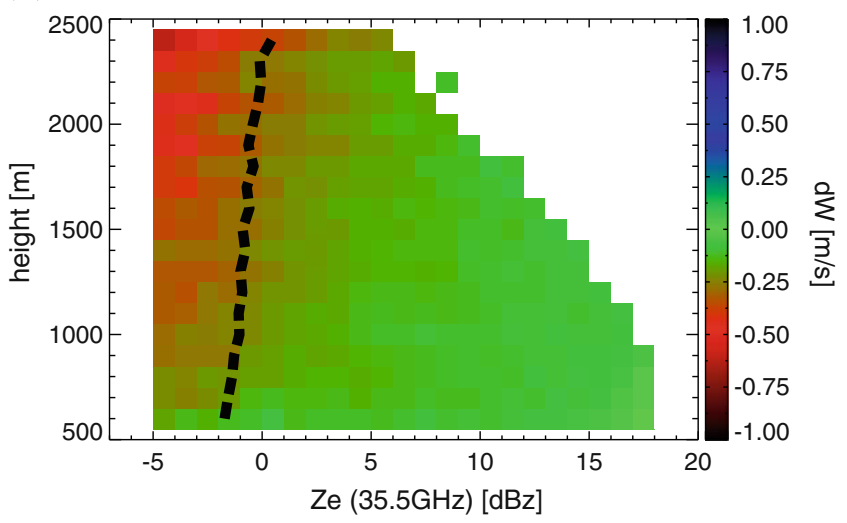

(converted into $35.5 \mathrm{GHz}$ equivalent values). b same as a but MRR $Z_{\mathrm{e}} \mathrm{s}$ are converted into $35.5 \mathrm{GHz}$ equivalent values. c Standard deviation of $\mathrm{d} Z_{\mathrm{e}}$ in $\mathbf{b}$. d Mean difference of the mean Doppler velocity $(W)$ between MRR and MIRA36 in $\mathrm{ms}^{-1}$. Each pixel in a-d contains a minimum number of 200 observations 
factors below that level will thus result in increasing $\mathrm{d} Z_{\mathrm{e}}$. This explanation is corroborated by the fact that the $99 \%$ quantile (Table 2) as a clear sky noise level (black dashed line) fits generally well to the region of strongly increasing $\mathrm{d} Z_{\mathrm{e}}$ values; therefore choosing the lower $99 \%$ quantile seems to be a reasonable assumption.

For values of $Z_{\mathrm{e}}$ above $12 \mathrm{dBz}$, we find a slight increase of $\mathrm{d} Z_{\mathrm{e}}$ values in the range of $1-2 \mathrm{~dB}$. These larger $\mathrm{d} Z_{\mathrm{e}}$ values agree well with the predicted $\mathrm{d} Z_{\mathrm{e}}$ increase in the $\mathrm{RT}$ simulations (Sect. 3) caused by a higher number of large snow particles. If the RT simulations represent the backscattering properties of natural snowfall, this enhancement should disappear when applying (Eq. 3).

Figure $6 \mathrm{~b}$ shows the resulting $\mathrm{d} Z_{\mathrm{e}}$ after converting the MRR $Z_{\mathrm{e}}$ into $35.5 \mathrm{GHz}$ equivalent values according to (3). The former $\mathrm{d} Z_{\mathrm{e}}$ increase at higher $Z_{\mathrm{e}}$ values disappears and the $\mathrm{d} Z_{\mathrm{e}}$ reduces to $<1 \mathrm{~dB}$ for the $Z_{\mathrm{e}}$ region larger than $2 \mathrm{dBz}$. Close to the noise level (below $3 \mathrm{dBz}$ ) the $\mathrm{d} Z_{\mathrm{e}}$ are found somewhat higher around $2 \mathrm{~dB}$. This effect cannot be fully explained so far, however, it seems that the MRR noise correction algorithm underestimates the noise level which particularly affects the lower $Z_{\mathrm{e}}$ values.

In addition to the mean $d Z_{\mathrm{e}}$ values, Fig. $6 \mathrm{c}$ shows the variability of $\mathrm{d} Z_{\mathrm{e}}$ for single profiles expressed as the standard deviation of $\mathrm{d} Z_{\mathrm{e}}$. The values increase almost continuously from 1.0 to $1.5 \mathrm{~dB}$ at $0-8 \mathrm{dBz}$ up to $2.5 \mathrm{~dB}$ at $15 \mathrm{dBz}$. The increasing variability of $\mathrm{dZ}_{\mathrm{e}}$ is consistent with the RT simulation results: The natural snow particle habit diversity has an increasing impact on $\mathrm{d} Z_{\mathrm{e}}$ at larger $Z_{\mathrm{e}}$ values, i.e. larger snow particle sizes. It is thus important to take this variability into account when using the $Z_{\mathrm{e}}$ values for $Z_{\mathrm{e}}-\mathrm{SR}$ relations.

The mean velocity differences $(\mathrm{d} W)$ of the two radars are found to be between 0 and $-0.3 \mathrm{~ms}^{-1}$ (Fig. 6d). Larger differences are found at larger heights and lower $Z_{\mathrm{e}}$ where noise becomes a dominant part of the signal. Below the MRR noise level the $\mathrm{d} W$ values are probably noise artefacts. The standard deviations of $\mathrm{d} W$ (not shown) are for the entire $Z_{\mathrm{e}}$ and height range below $0.5 \mathrm{~ms}^{-1}$ indicating a high agreement of the two velocity measurements even for single profiles.

An example for a typical snowfall event apparent in both the MRR and the MIRA36 data is presented in Fig. 7. The time-height cross sections of the MIRA36 (Fig. 7a) and the frequency corrected MRR (Fig. 7b) observations reveal a very high structural agreement. (Note that for better comparison the MIRA36 $Z_{\mathrm{e}}$ values have been limited to the $Z_{\mathrm{e}}$ range, which can be captured by the MRR.) The MRR reveals even small scale structures up to its maximum height. For better comparison of the $Z_{\mathrm{e}}$ values, we display them in Fig. 7c also as a scatter plot. The larger values between 5 and $15 \mathrm{dBz}$ agree very well as expected from the former statistical analysis (Fig. 6). At the lowest
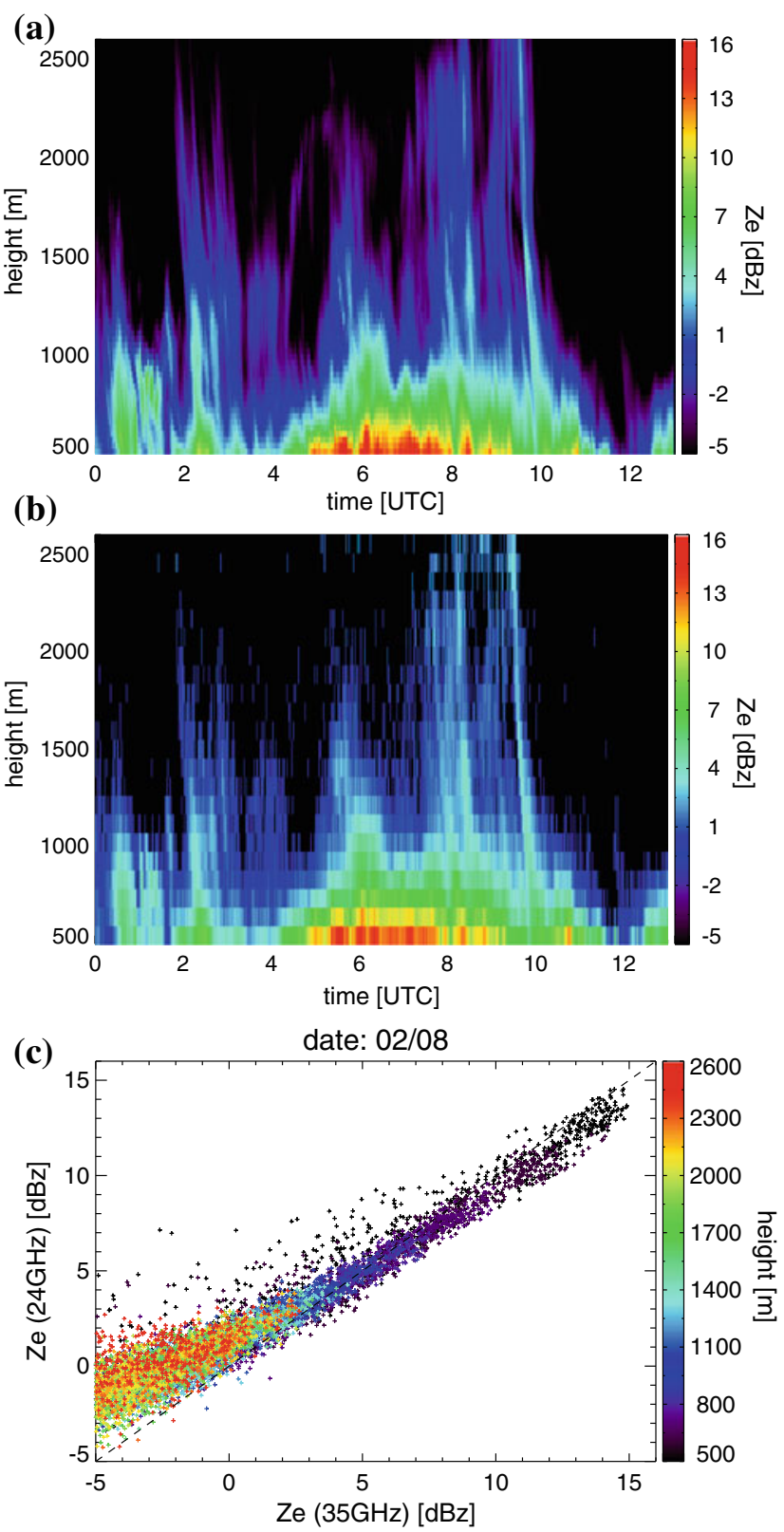

Fig. 7 Time-height cross sections of effective reflectivity factor $Z_{\mathrm{e}}$ $(\mathrm{dBz})$ for a MIRA36 and $\mathbf{b}$ MRR on 08 February 2009. $Z_{\mathrm{e}}$ values from both radar systems and for all heights (color code) are plotted as scatter plot in c; direct line is dashed. All MRR values have been converted into $35.5 \mathrm{GHz}$ equivalent $Z_{\mathrm{e}}$ s according to Eq. 3. Note that the MIRA36 reflectivity values have been reduced to the MRR $Z_{e}$ range

$Z_{\mathrm{e}}$ values the MRR $Z_{\mathrm{e}}$ reach the noise level and remain between 0 and $-4 \mathrm{dBz}$.

\subsection{Snowfall rates and total snow accumulation}

The MRR-MIRA36 comparison confirmed the reliability of both the clear sky noise level estimate and the applicability of the $Z_{\mathrm{e}}$ conversion (Eq. 3). We will now evaluate the 
effects of the limitations of the MRR on the derived snowfall rates and the amount of snow accumulated over a certain time. To this goal we selected three recently published $\mathrm{Z}_{\mathrm{e}}-\mathrm{SR}$ relations for $35 \mathrm{GHz}$. Usually, $\mathrm{Z}_{\mathrm{e}}-\mathrm{SR}$ relations are formulated as power laws in the form

$Z_{\mathrm{e}}=a \cdot S R^{b}$,

with $Z_{\mathrm{e}}$ in $\mathrm{mm}^{6} \mathrm{~m}^{-3}$, the liquid equivalent $\mathrm{SR}$ in $\mathrm{mm} \mathrm{h}^{-1}$, and $a, b$ coefficients which are summarized in Table 3 for several relations. The $Z_{\mathrm{e}}-\mathrm{SR}$ relations are extremely sensitive to the chosen snow particle habit and SSD which can be seen in the large variability of the $a$ and $b$ coefficients. The selected relations in Table 3 cover the variability of a large set of different particle habits and SSD realizations: Kulie and Bennartz (2009) compared in their studies 22 different snow particle habits with a SSD parameterization that is based on large dataset of aircraft observations. In their study, they identify the $Z_{\mathrm{e}}-\mathrm{SR}$ relation for the three bullet rosette (LR3) as an average of the different relations. Further, they select the aggregate ice particle (HA) and the low-density spherical snow particle (SS) to represent the variability of the different relations. Matrosov (2007) found for horizontally aligned ellipsoids consisting of an ice-air mixture and with an aspect ratio of 0.6 that their scattering properties are representative for natural snow aggregates. Noh et al. (2006) derive their $\mathrm{Z}_{\mathrm{e}}-\mathrm{SR}$ relation with an average of sector snowflakes and dendrites that are also used in this study.

Figure 8 shows the resulting SR, which can differ up to one order of magnitude depending on the chosen relation. Taking into account the MRR noise level (at $600 \mathrm{~m}$ height), we find that values of SR below $0.01-0.15 \mathrm{~mm} \mathrm{~h}^{-1}$ are likely to be missed by the MRR.

The retrieval quality of snow accumulation by the MRR can only be estimated if the probability density function (PDF) of the $\mathrm{SR}$ (or $Z_{\mathrm{e}}$ values) is known. From the TOSCA dataset we can derive a $Z_{\mathrm{e}}$-probability density function (PDF) using the MIRA36 observations. It should be noted that the PDF might be only valid for this particular location since clouds and precipitation processes can be

Table 3 Prefactor $a$ and exponent $b$ (Eq. 5) for published $\mathrm{Z}_{\mathrm{e}}-$ snowfall rate relations for dry snowfall and $35 \mathrm{GHz}$ (see text for details)

\begin{tabular}{lrl}
\hline Reference & \multicolumn{1}{l}{$a$} & \multicolumn{1}{l}{$b$} \\
\hline Kulie and Bennartz (2009), LR3 & 24.04 & 1.51 \\
Kulie and Bennartz (2009), HA & 313.29 & 1.85 \\
Kulie and Bennartz (2009), SS & 19.66 & 1.74 \\
Matrosov (2007) & 56.00 & 1.20 \\
Noh et al. (2006) & 88.97 & 1.04 \\
\hline
\end{tabular}

The effective reflectivity factor $\left(Z_{\mathrm{e}}\right)$ has units of $\mathrm{mm}^{6} \mathrm{~m}^{-3}$, while the snowfall rate (SR) is in units of $\mathrm{mm} \mathrm{h}^{-1}$

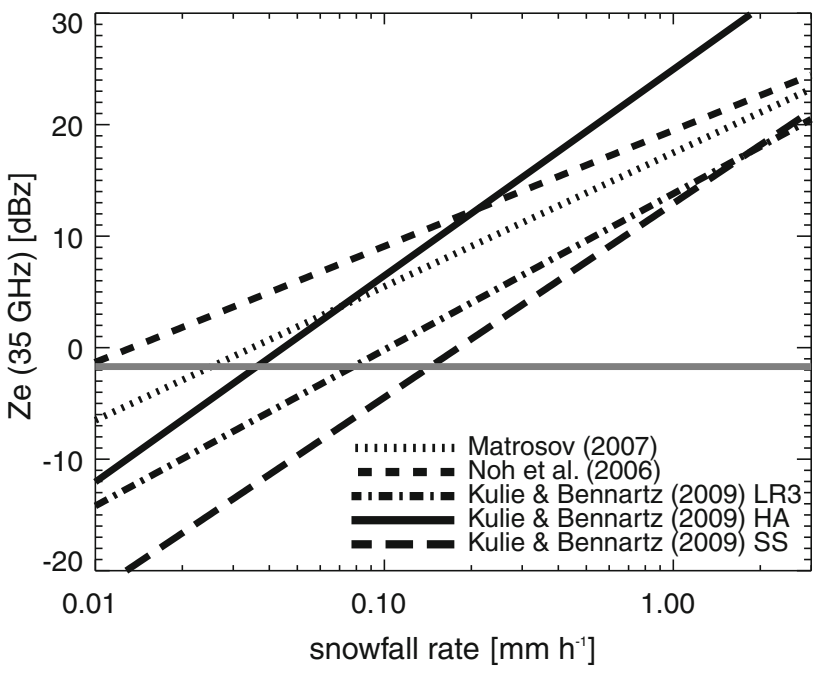

Fig. 8 Effective radar reflectivity factor $Z_{\mathrm{e}}(\mathrm{dBz})$ at $35.5 \mathrm{GHz}$, as a function of snowfall rate $\left(\mathrm{mm} \mathrm{h}^{-1}\right)$ for five different $Z_{\mathrm{e}}$-snowfall rate relations from literature (see also details in the text). The grey solid line denotes the estimated clear sky noise threshold of the MRR at $600 \mathrm{~m}$ height (converted to $35.5 \mathrm{GHz}$ equivalent values)

significantly influenced by the surrounding orography. However, a comparison with very recently published $Z_{\mathrm{e}} / \mathrm{SR}$ distributions for northern mid-latitudes based on CloudSat observations (Kulie and Bennartz 2009) reveals that the UFS data show a more general behavior and are not so much dependent on the specific conditions of the UFS site.

The $\mathrm{Z}_{\mathrm{e}}$-PDF for the 6-month time period has been derived from the MIRA36 measurements (Fig. 9). The probability of large $Z_{\mathrm{e}}$ values decreases with increasing height and is largest close to ground as expected. In the lowest $1,500 \mathrm{~m}$ the $Z_{\mathrm{e}}$ values range mostly between -10 and $10 \mathrm{dBz}$. At $600 \mathrm{~m}$ height level (used for estimating the surface snowfall rate) about $50 \%$ of the MIRA36 $Z_{\mathrm{e}}$ values

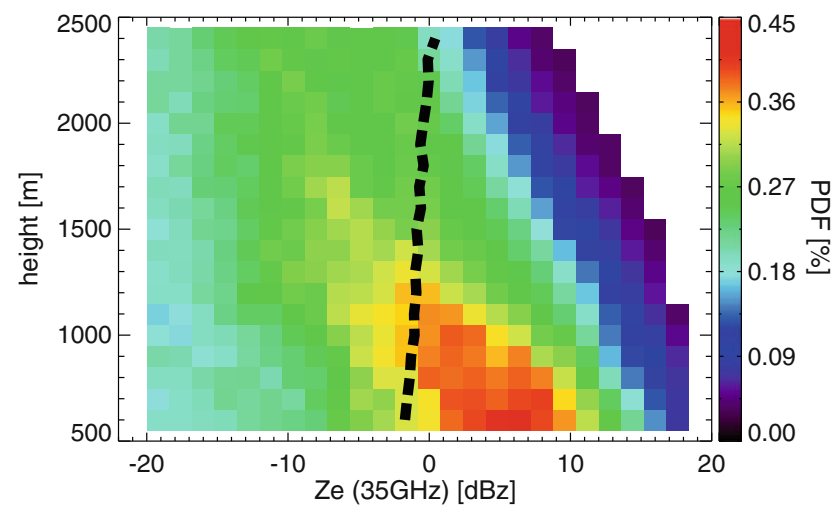

Fig. 9 2D probability density function (percentage color coded, total number of measurements is 749.686 taking into account all bins) of MIRA36 effective radar reflectivity factor $Z_{\mathrm{e}}(\mathrm{dBz})$ depending on $Z_{\mathrm{e}}$ and height. Each pixel contains a minimum number of 200 observations. The dashed black line denotes the clear sky noise level of the MRR (converted into $35.5 \mathrm{GHz}$ equivalent $Z_{\mathrm{e}}$ ) 
are larger than the MRR noise level. When we assume a minimum $Z_{\mathrm{e}}$ threshold of $-10 \mathrm{dBz}$ for precipitating clouds (which would exclude snowfall rates up to a maximum of about $0.05 \mathrm{~mm} \mathrm{~h}^{-1}$ according to Fig. 8), the MRR would still detect about $70 \%$ of the precipitation cases. Figure 10 illustrates how the different SRs contribute to the snow accumulation. The $Z_{\mathrm{e}}-\mathrm{SR}$ relation from Matrosov (2007) has been exemplarily applied to the 6-month MIRA36 data set and to the converted MRR $Z_{\mathrm{e}}$ (Fig. 10a) since it is close to the mean of the $Z_{\mathrm{e}}-\mathrm{SR}$ relations shown in Fig. 8, especially for larger snowfall rates. It should be noted, that the actual snow accumulation for the considered time period is probably higher since $46 \%$ of the data have been
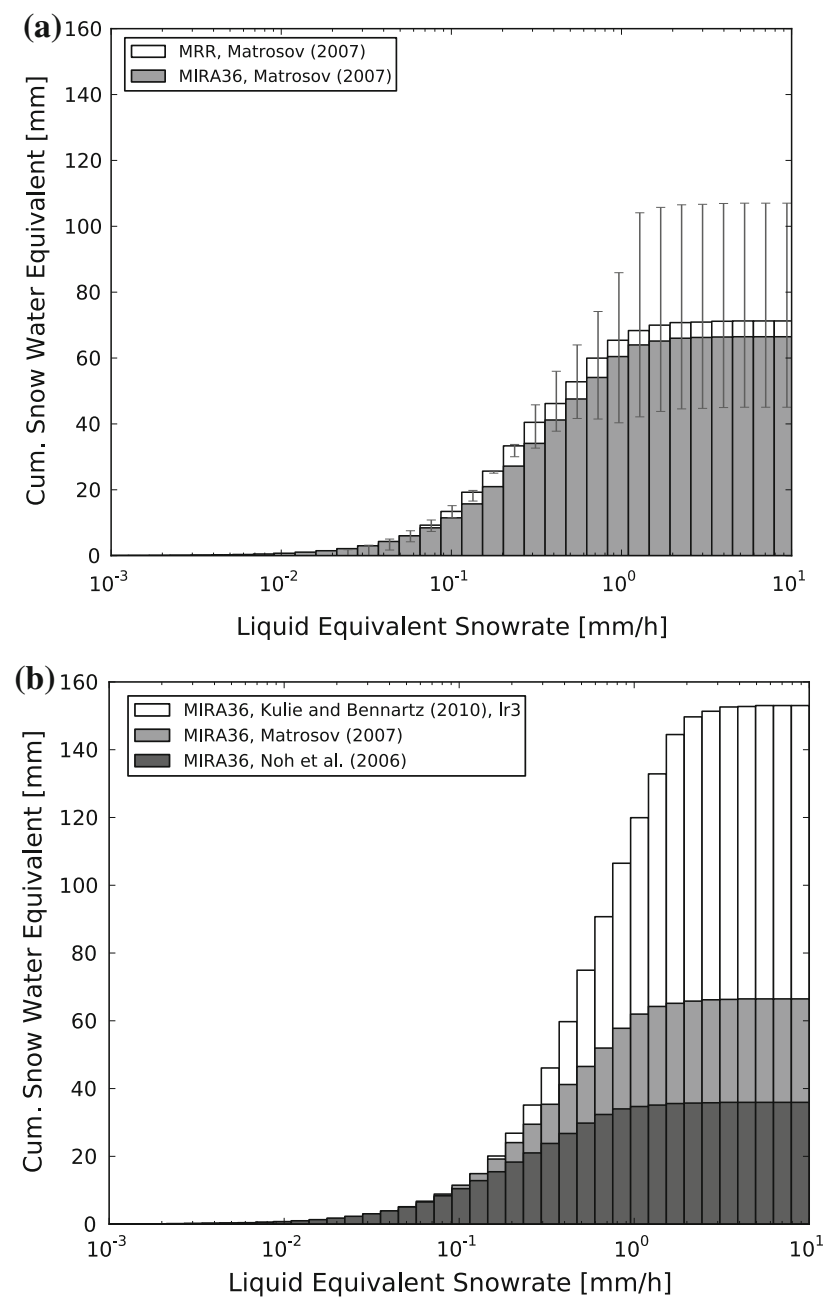

Fig. 10 a The Matrosov (2007) $Z_{\mathrm{e}}-\mathrm{SR}$ relation has exemplarily been applied to the MRR measurements (white bars) and to the simultaneous MIRA36 dataset (light grey) at $600 \mathrm{~m}$ height. The MRR values have been converted into $35.5 \mathrm{GHz}$ equivalent values. The cumulative snow water equivalent $(\mathrm{mm})$ is shown as a function of snowfall rates $\left(\mathrm{mm} \mathrm{h}^{-1}\right)$. The error bars indicate the uncertainty in the estimated cumulative snow water equivalent due to the standard deviation of $\mathrm{d} Z_{\mathrm{e}}$ at $600 \mathrm{~m}$ height (see Fig. 6c). b Similar to a however, three different $Z_{\mathrm{e}}-\mathrm{SR}$ relations are applied only to the MIRA36 data at $600 \mathrm{~m}$ height filtered out by quality checks (mainly due to snow/ice covered radar antennas).

The total snow accumulation (liquid equivalent) estimated from the MIRA36 (MRR) observations is 66 (71) $\mathrm{mm}$. The $7 \%$ higher MRR snow accumulation estimate can be related to the slight $Z_{\mathrm{e}}$ overestimation of the MRR at $Z_{\mathrm{e}}$ between 0 and $5 \mathrm{dBz}$ (see Fig. $6 \mathrm{~b}$ and discussion). When the standard deviation of the $\mathrm{d} Z_{\mathrm{e}}$ is applied as a rough uncertainty estimate for the MRR observations, the obtained values in terms of total snow accumulation vary between 45 and $107 \mathrm{~mm}$ (63 and 151\% of the mean). For comparison, the estimated precipitation rate based on the standard MRR retrieval for liquid rain would result in a total amount of precipitation of $164 \mathrm{~mm}$, which illustrates the necessity to modify the retrieval for snowfall observations.

Obviously, the smaller SR ignored by the MRR do not significantly contribute to the snow accumulation for this period because the largest contribution stems from SR between 0.1 and $0.8 \mathrm{~mm} \mathrm{~h}^{-1}$ which correspond to a $Z_{\mathrm{e}}$ range between 5 and $16 \mathrm{dBz}$. These findings are in general agreement with results based on CloudSat observations at $1,300 \mathrm{~m}$ height level where SR between 0.1 and $1.0 \mathrm{~mm} \mathrm{~h}^{-1}$ have been found to contribute most to the average snow amount (Kulie and Bennartz 2009).

Three hourly manual snow accumulation observations are available at the nearby Zugspitze $(300 \mathrm{~m}$ above the UFS) by the German Weather Service. These observations are probably affected by wind drift and orographic effects. Nevertheless, their measured value of $65 \mathrm{~mm}$ for the 6-month period (observation periods restricted to the considered radar time periods) confirms that the order of magnitude of the derived radar estimates is reasonable.

Besides the uncertainty introduced by different radar sensitivities, however, one of the largest sources of uncertainty remains the uncertainty of the $\mathrm{Z}_{\mathrm{e}}-\mathrm{SR}$ relations. Figure $10 \mathrm{~b}$ illustrates this variability by showing the results of three exemplary $Z_{\mathrm{e}}-\mathrm{SR}$ relations applied to the $\mathrm{Z}_{\mathrm{e}}-\mathrm{PDF}$ of the MIRA36 at $600 \mathrm{~m}$ height: the estimated total snow accumulation varies due to the different relations between 36 and $153 \mathrm{~mm}$ snow water equivalent. This variability is about a factor 2 larger compared to the uncertainty of the two different radar systems.

\section{Conclusions}

In this paper we investigated the potential of a vertically pointing low-power FM-CW, K-band Doppler radar to observe dry snowfall in cloud layers below 3-km height. The analysis is based on a 6-month data set from collocated measurements of a MRR and a MIRA36 cloud radar that were collected during the TOSCA campaign at UFS. 
The two radar systems operate at wavelengths which are close to the upper size limit of typical snowflakes. Thus, Mie effects are likely to influence the observed $Z_{\mathrm{e}}$ values. In order to quantify the Mie effect, we investigated the comparability of the $Z_{\mathrm{e}}$ from the MRR and the MIRA36. RT simulations with snowfall differing by snow particle type (habit), SSD and SWC were performed. We found that due to the frequency difference of $11.4 \mathrm{GHz}$ a mean $Z_{\mathrm{e}}$ difference of several $\mathrm{dBz}$ can be introduced depending particularly on habit and SSD. Based on these results, we derived an average relationship that allows us to convert $24.1 \mathrm{GHz} Z_{\mathrm{e}}$ into $35.5 \mathrm{GHz}$ equivalent values. This conversion enabled us to directly compare the observations of the two radar systems. While the differences in the mean Doppler velocity were found to be below $0.3 \mathrm{~ms}^{-1}$, the $Z_{\mathrm{e}}$ differences varied between 0 and $2 \mathrm{~dB}$. After applying a frequency correction to the MRR values, the remaining $\mathrm{d} Z_{\mathrm{e}}$ are below $1 \mathrm{~dB}$ for $Z_{\mathrm{e}}$ greater than $3 \mathrm{dBz}$.

In order to assess the potential of the MRR for snowfall observations, an accurate estimation of the instrument noise level is essential because of the low reflectivity values of snowfall. The direct comparison of the MRR with MIRA36 clearly revealed the transition of the MRR data from signal into the noise floor at lower values. The noise level found in this direct comparison agrees well with the noise levels estimated by an analysis of several clear sky observations. Thus, the MRR noise level can be easily estimated also without a high-end system for direct comparison. Slightly higher $\mathrm{d} Z_{\mathrm{e}}$ close to the noise level indicate, however, that there is probably still room for improvements of the noise estimation of the MRR.

One of the basic scientific questions of this paper was, whether the limited sensitivity of the MRR has a significant impact on the estimated snow accumulation. To answer this question, we used the dataset of MIRA36 $Z_{\mathrm{e}}$ observations of the whole time period and applied recently published $Z_{\mathrm{e}}-\mathrm{SR}$ relations to the data. Due to the limited sensitivity of the MRR, snowfall rates below $0.01-0.15 \mathrm{~mm} \mathrm{~h}^{-1}$ are probably missed by the MRR depending on snow particle habit and snow particle size distributions. The effect of such low snowfall rates on total snow accumulation was, however, surprisingly low. We have to admit, however, that these results are representative only for locations with similar $Z_{\mathrm{e}}$ distributions. The remaining $7 \%$ difference in the estimated total snow accumulation from both instruments is mainly due to the slight $Z_{\mathrm{e}}$ overestimation of the MRR at low $Z_{\mathrm{e}}$ values. In addition, considerable variability is also introduced by the various snow particle habits that cause deviations from the mean $Z_{\mathrm{e}}$ conversion relation. However, as several studies have showed before, the main source of uncertainty in the quantitative estimation of snowfall remains the huge variability introduced by the different $Z_{\mathrm{e}}-\mathrm{SR}$ relations.
Overall, the MRR was found to be a valuable instrument to observe mid-latitude snowfall at heights below $3 \mathrm{~km}$. Of course, the instrument has significant limitations compared to standard cloud radars mainly due to its limited sensitivity and height resolution. However, the MRR provides also great advantages for dry snowfall observations in remote areas due to its relatively low power consumption, maintenance, and size. If the noise level can be further reduced (e.g. by using the raw data and improving the mean noise level estimation technique) and thus the MRR sensitivity to low SR can be enhanced, the MRR could also be used for climatological studies e.g. in the polar regions. The much lower costs of the MRR (only 1/20 of the MIRA36) makes it particularly attractive for radar network applications. Data from already existing MRR networks for rain observations could be reprocessed for dry snowfall observations.

Even if the quantitative estimation of snowfall rate using a single-frequency radar is affected by large uncertainties, the MRR observations can be used to distinguish between snow/ice, rain and melting layer region within the cloud. Particularly in polar regions the discrimination between blowing snow and snowfall is a critical issue and impossible to achieve with in situ disdrometers or snow accumulation measurements. Using the vertical information of the MRR this discrimination can be achieved since blowing snow is limited to the lowest height levels while snowfall is usually connected to a vertically extended column of hydrometeors.

Acknowledgments The authors wish to express their gratitude to G. Liu for providing his ice particle single scattering database and especially his additional calculations for the MRR frequency. We also acknowledge the work done by M. Hagen (DLR) and L. Hirsch (MPI Hamburg) on the maintenance of the two radars during TOSCA. Further, the authors thank P. Saavedra (University of Bonn) for his work in MRR data processing. The MRR in Longyearbyen was operated by REPAIR (Retrieval and Estimation of Precipitation in the Arctic and Immediate Region) and was kindly supported by C. Kidd (University of Birmingham), F. Sigernes and B. Merkel (both University Centre in Svalbard). This work is part of the TOSCA project funded by the German Science Foundation (DFG) under grant LO 901/3-1.

Open Access This article is distributed under the terms of the Creative Commons Attribution Noncommercial License which permits any noncommercial use, distribution, and reproduction in any medium, provided the original author(s) and source are credited.

\section{References}

Atlas D, Srivastava R, Sekhon R (1973) Doppler radar characteristics of precipitation at vertical incidence. Rev Geophys Space Phys 11:1-35. doi:10.1029/RG011i001p00001

Boudala FS, Isaac GA, Cober SG, Fu Q (2004) Liquid fraction in stratiform mixed-phase clouds from in situ observations. Q J R Meteorol Soc 130:2919-2931. doi:10.1256/qj.03.153 
Braham RR (1990) Snow particle-size spectra in lake effect snows. J Appl Meteorol 29:200-207. doi:10.1175/1520-0450(1990)029 $<0200$ :SPSSIL $>2.0$.CO;2

Brandes EA, Ikeda K, Zhand G, Schönhuber M, Rasmussen RM (2007) A statistical and physical description of hydrometeor distributions in Colorado snowstorms using a Video Disdrometer. J Appl Meteorol Clim 46:634-650. doi:10.1175/JAMC 2489.1

Brandes EA, Ikeda K, Thompson G, Schönhuber M (2008) Aggregate terminal velocity/temperature relations. J Appl Meteorol Clim 47:2729-2736. doi:10.1175/2008JAMC1869.1

Cha J-W, Chang K-H, Yum SS, Choi Y-J (2009) Comparison of the bright band characteristics measured by Micro Rain Radar (MRR) at a mountain and a coastal site in South Korea. Adv Atmos Sci 26:211-221. doi:10.1007/s00376-009-0211-0

Ellis TD, L'Ecuyer T, Haynes JM, Stephens GL (2009) How often does it rain over the global oceans? The perspective from CloudSat. Geophys Res Lett 36:L03815. doi:10.1029/2008 GL036728

Evans KF, Stephens GL (1991) A new polarized atmospheric radiative transfer model. J Quant Spectrosc Radiat 46:413-423. doi:10.1016/0022-4073(91)90043-P

Kneifel S, Löhnert U, Battaglia A, Crewell S, Siebler D (2010) Snow scattering signals in ground-based passive microwave radiometer measurements. J Geophys Res 115:D16214. doi:10.1029/2010JD 013856

Kulie MS, Bennartz R (2009) Utilizing space-borne radars to retrieve dry snowfall. J Appl Meteorol Clim 48:2564-2580. doi:10.1175/ 2009JAMC2193.1

Liu G (2008) A database of microwave single-scattering properties for nonspherical ice particles. Bull Am Meteor Soc 89:15631570. doi:10.1175/2008BAMS2486.1

Löffler-Mang M, Joss J (2000) An optical disdrometer for measuring size and velocity of hydrometeors. J Atmos Ocean Tech 17: 130-139. doi:10.1175/1520-0426(2000)017<0130:AODFMS> 2.0.CO;2

Löffler-Mang M, Kunz M, Schmid W (1999) On the performance of a low-cost K-band Doppler radar for quantitative rain measurement. J Atmos Ocean Tech 16:379-387. doi:10.1175/15200426(1999)016<0379:OTPOAL > 2.0.CO;2
Löhnert U, Kneifel S, Battaglia A, Hagen M, Hirsch L (2011) A multi-sensor approach towards a better understanding of snowfall microphysics: the TOSCA project. Bull Am Meteorol Soc. doi:10.1175/2010BAMS2909.1

Matrosov SY (2007) Modeling backscattering properties of snowfall at millimeter wavelengths. J Atmos Sci 64:1727-1736. doi: 10.1175/JAS3904.1

Matrosov SY, Shupe MD, Djalalova IV (2008) Snowfall retrievals using millimeter-wavelength cloud radars. J Appl Meteorol Clim 47:769-777. doi:10.1175/2007JAMC1768.1

Melchionna S, Bauer M, Peters G (2008) A new algorithm for the extraction of cloud parameters using multipeak analysis of cloud radar data-first application and preliminary results. Meteorol Z 17:613-620. doi:10.1127/0941-2948/2008/0322

Noh Y-J, Liu G, Seo E-K, Wang JR, Aonashi K (2006) Development of a snowfall retrieval algorithm at high microwave frequencies. J Geophys Res 111:D22216. doi:10.1029/2005JD006826

Peters G, Fischer B, Andersson T (2002) Rain observations with a vertically looking Micro Rain Radar (MRR). Boreal Environ Res 7:353-362

Peters G, Fischer B, Münster H, Clemens M, Wagner A (2005) Profiles of raindrop size distributions as retrieved by Microrain Radars. J Appl Meteorol 44:1930-1949. doi:10.1175/JAM2316.1

Petty GW, Huang W (2010) Microwave backscatter and extinction by soft ice spheres and complex snow aggregates. J Atmos Sci 67:769-787. doi:10.1175/2009JAS3146.1

Strauch RG (1976) Theory and Application of the FM-CW Doppler radar. Ph.D. thesis, Electrical Engineering, University of Colorado

Tokay A, Hartmann P, Battaglia A, Gage KS, Clark WL, Williams CR (2009) A field study of reflectivity and $Z-R$ relations using vertically pointing radars and disdrometers. J Atmos Ocean Tech 26:1120-1134. doi:10.1175/2008JTECHA1163.1

Van Baelen J, Tridon F, Pointin Y (2009) Simultaneous X-band and $\mathrm{K}$-band study of precipitation to derive specific Z-R relationships. Atmos Res 94:596-605. doi:10.1016/j.atmosres.2009. 04.003

Yuter SE, Houze RA (2003) Microphysical modes of precipitation growth determined by vertically pointing radar in orographic precipitation during MAP. Q J Roy Meteor Soc 129:455-476. doi:10.1256/qj.01.216 